\title{
Time-Lapse Embryo culture: A better understanding of embryo development and clinical application
}

\author{
Silvana Márquez-Hinojosa ${ }^{1}$, Luis Noriega-Hoces ${ }^{2}$, Luis Guzmán ${ }^{1}$ \\ ${ }^{1}$ PRANOR Laboratorio. Grupo de Reproducción Asistida, Lima, Peru \\ ${ }^{2}$ Clínica Concebir. Calle Los Olivos 364, San Isidro, Lima, Peru
}

\begin{abstract}
Conventional embryo assessment is performed by removing embryos from incubators at least once a day. However, it is static and limited to specific time points, reducing the amount of information that could potentially be obtained. Fortunately, the time-lapse system is a powerful technology that enables to observe embryo development progression by image acquisition at recurrent time intervals, without interfering in the culture conditions. There are numerous studies that used timelapse incubators, focusing on embryo kinetics, patient characteristics and clinical outcomes. This review aims to find agreements in the literature concerning embryo kinetics and patient characteristics: age, body mass index, smoking habit, polycystic ovary syndrome and endometriosis; as well as culture conditions that involved culture media and oxygen concentration. Furthermore, they showed differences according to ploidy status, direct/ reverse cleavage, gender and the potential association between embryo collapse and clinical outcomes.
\end{abstract}

Keywords: blastocyst, aneuploidy, embryo culture

\section{INTRODUCTION}

Since the beginning of assisted reproduction techniques (ART), morphology has been used as a standard method for embryo selection, generating comparable clinical outcomes among laboratories (Ludwig et al., 2000). Currently, several laboratories are culturing embryos until the blastocyst stage, and the best morphology-embryo is selected for embryo transfer (Scott et al., 2000).

The Time-Lapse (TL) system in ART was first described by Payne et al. (1997), who reported morphokinetic events in early embryo development stages, some of them were: second polar body extrusion, pronuclear formation (maternal and paternal) and cellular cleavage. Morphokinetics enables to compare time frames and dysmorphic events during embryo development (Payne et al., 1997). With all this information, algorithms have been proposed with the aim to increase implantation rates in ART (Sakkas et al., 1998; Gardner et al., 2015).

Embryo culture in TL incubators enabled us to continuously monitor embryo development, without interfering with culture conditions (temperature, gas concentrations and $\mathrm{pH}$ ); thus, decreasing the negative impact on embryo development (Kahraman et al., 2020) and minimizing the negative effect of standard embryo evaluation under conventional microscopes.

The clinical effectiveness of TL systems is still controversial. A meta-analysis concluded that the TL was associated with a significantly higher ongoing pregnancy, live birth rate and significantly lower early pregnancy loss in comparison to the conventional incubator and morphological selection (Pribenszky et al., 2017); whereas a recent Cochrane review concluded that there are insufficient evidence to support a higher live birth rate when the TL system is used with the aid of software assessment (Armstrong et al., 2018). Furthermore, similar meta-analyses have demonstrated some clinical benefits using TL (Armstrong et al., 2018; Chen et al., 2017). This study aimed to describe how morphokinetic parameters differ according to patient characteristics and culture conditions during embryo development.

\section{PATIENT CHARACTERISTICS AND EMBRYO MORPHOKINETICS \\ Age}

It is widely accepted that older women have diminished ovarian reserve and poor oocyte quality (Navot et al., 1991). Additionally, old patients have higher chances to produce aneuploid embryos, which reduce pregnancy rates (Grøndahl et al., 2017).

Retrospective studies concluded that there are no significant differences in morphokinetic parameters (Tables 1 and 2) during cleavage stages between the embryos from advanced maternal age and those of younger women (Hickman et al., 2013; Silva et al., 2015; Gryshchenko et al., 2014; Warshaviak et al., 2019). By contrast, two retrospective studies reported a significantly faster cleavage in some kinetic parameters in younger patients when compared to older ones (Akarsu et al., 2017; Dal Canto et al., 2021). Nevertheless, these differences are not evident in patients aged $\geq 37$ years (Dal Canto et al., 2021).

On the other hand, morphokinetics is faster in later stages (tM, tSB, tB and tHatched) in younger patients ( $\leq 36$ years) than their counterparts; it becomes slower with increasing maternal age (Hickman et al., 2013; Silva et al., 2015).

\section{Body Mass index (BMI)}

BMI is defined as the body weight in kilograms divided by the square of height in meters; it is universally expressed in units of $\mathrm{kg} / \mathrm{m}^{2}$, used to broadly categorize a person as underweight $\left(<18,5 \mathrm{~kg} / \mathrm{m}^{2}\right)$, normal weight (18.5 to $24.5 \mathrm{~kg} / \mathrm{m}^{2}$ ), overweigh ( 25 to $30 \mathrm{~kg} / \mathrm{m}^{2}$ ) or obese (over $30 \mathrm{~kg} / \mathrm{m}^{2}$ ) (WHO, 2020).

\section{Overweight and obesity}

Obese women need longer time to become pregnant (Gesink Law et al., 2007; Wise et al., 2010) and their risk of infertility is almost three times higher compared to non-obese women (Zaadstra et al., 1993). Obese women who underwent fertility treatments have lower number of retrieved and mature oocytes, poorer embryo quality (Bellver et al., 2013), lower fertilization (Krizanovská et al., 2002) and increased miscarriage rates (Rittenberg et al., 2011).

Classical morphological evaluation does not seem to be useful for analyzing the impact of obesity on embryo quality (Bellver et al., 2010; Shah et al., 2011). However, morphokinetic parameters showed differences. A recent study, found that $\mathrm{t} 5$ and $\mathrm{t} 8$ were delayed in obese and in overweight women in relation to the normal-weight group 


\begin{tabular}{|c|c|}
\hline Morphokinetic variables & Description \\
\hline tPB & Appearance of second polar body \\
\hline tPNa & Appearance of the first pronuclei \\
\hline tPN & Appearance of both pronuclei \\
\hline tPNf & Time when both pronuclei had faded \\
\hline t2 & Time to 2-cell embryo \\
\hline t3 & Time to 3-cell embryo \\
\hline t4 & Time to 4-cell embryo \\
\hline t5 & Time to 5-cell embryo \\
\hline t6 & Time to 6-cell embryo \\
\hline t7 & Time to 7-cell embryo \\
\hline t8 & Time to 8-cell embryo \\
\hline t9 & Time to 9-cell embryo \\
\hline tSC & Time from insemination to initiation of compaction \\
\hline tM & Time from insemination to formation of a morula, completion of compaction process \\
\hline tSB & Time from insemination to star blastulation \\
\hline tB & Time form insemination to formation of a full blastocyst \\
\hline tEB & Time to expanded blastocyst \\
\hline $\mathrm{tH}$ & Time to hatching blastocyst, the trophectoderm herniation through the zona pellucida \\
\hline tHatched & Time to hatched blastocyst, the embryo has full escaped the zona pellucida \\
\hline Duration variables & Description \\
\hline $\mathrm{cc1}$ & Time of first cell cycle (t2- tPB) \\
\hline cc2 & Time of second cell cycle ( $\mathrm{t} 3-\mathrm{t} 2$ ), from 2 to 3 cells \\
\hline $\operatorname{cc3}$ & Time of third cell cycle (t5-t3), from 3 to 5 cells \\
\hline s2 & Time of synchrony of the second cycle (t4-t3), from 2 to t 4 cells \\
\hline s3 & Time of synchrony of the third cell cycle (t8-t5), from t5 to 8 cells. \\
\hline
\end{tabular}

(Bartolacci et al., 2019); while another study reported that embryos generated from obese and normal-weight infertile women showed similar cleavage patterns, but both groups were slower in early cleavage stages (t2, t3, t4 and t5) than embryos from fertile donors (control) (Bellver et al., 2013). In contrast, other studies reported that higher BMI $\left(>25 \mathrm{~kg} / \mathrm{m}^{2}\right)$ was associated with earlier occurrence of tM (Leary et al., 2015) as well as earlier tPN, tPNf, t2, t4, t6, t7 and t8 and S2 than normal-weight women (Mumusoglu et al., 2017).

\section{Under weigh}

There is no strong evidence that underweight women are associated with menstrual abnormalities or infertility. However, TL systems have enabled to study the morphokinetics of these patients. A study found that underweight women presented later $\mathrm{t} 4, \mathrm{t} 5, \mathrm{t} 6$ and $\mathrm{t} 8$ cell stages than their normal-weight, overweight and obese counterparts (Lammers et al., 2013). By contrast, a study reported that BMI (low or high) does not impact embryo morphokinetics (Silva et al., 2015).

\section{Polycystic Ovary Syndrome (PCOS)}

PCOS affects $5-10 \%$ of women of reproductive age. It is considered a heterogeneous disorder. It is identified using the Rotterdam criteria, in which two out of three of the following conditions must be met: the presence of oligoand/ or anovulation, clinical and/ or biochemical signs of hyperandrogenism and polycystic ovaries.
Morphokinetic parameters in hyper-androgenic PCOS women had a delay in early stages (from tPNf to t8) compared with embryos from non-PCOS regular cycles, but there was no kinetic difference between normo-androgenic PCOS and control women (Wissing et al., 2014). In addition, another report stated that embryos generated from PCOS patients had long developmental timings ( $t P N f, t 2$, t3, t4, t5, t6, t7 and t8) compared to normo-ovulatory women (Tabibnejad et al., 2019).

Nevertheless, other studies reported a faster development in PCOS and hyper-androgenic patients when compared to embryos from non-PCOS patients during the cleavage stage $\left(t 5, t 6, t 7, t 8, t 9\right.$ and $4^{\text {th }}$ cleavage division (from 8-cells to 9 or more cells), time to tSC and tM (Sundvall et al., 2015; Chappell et al., 2017; 2020).

On the other hand, a recent paper documented any significant differences in early embryonic development between the PCOS group and control patients. However, we must emphasize that in this study, the embryos were cultured until day 2 (Tam Le et al., 2019).

Finally, the current available data concluded that the implantation rate and the clinical pregnancy rate did not differ between PCOS patients and their control counterparts (Wissing et al., 2014; Sundvall et al., 2015; Tabibnejad et al., 2019; Tam Le et al., 2019). Retrospective studies concluded that PCOS patients have a trend towards a lower live birth rate and higher spontaneous abortion rates (Chappell et al. 2017; 2020). 


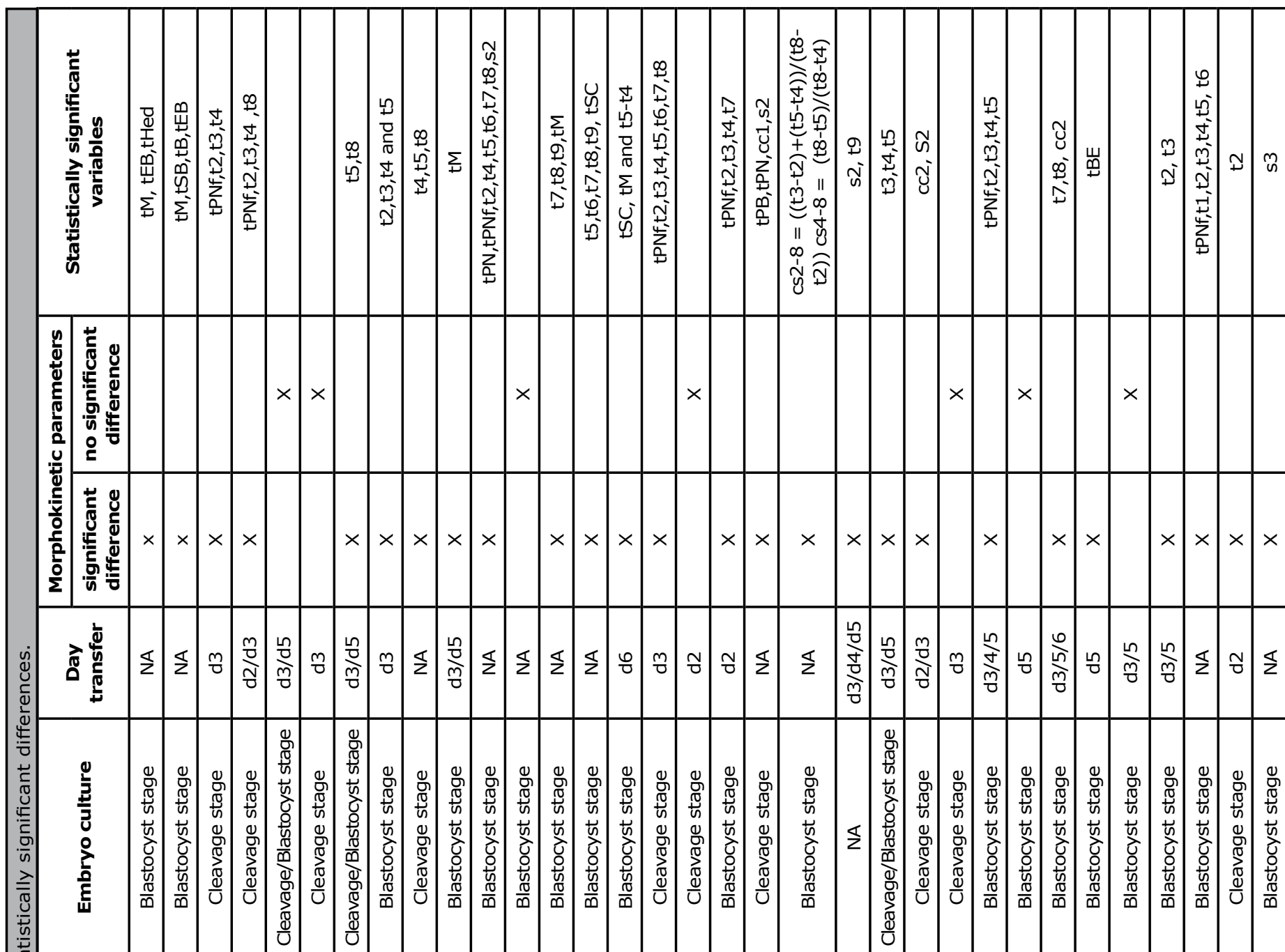

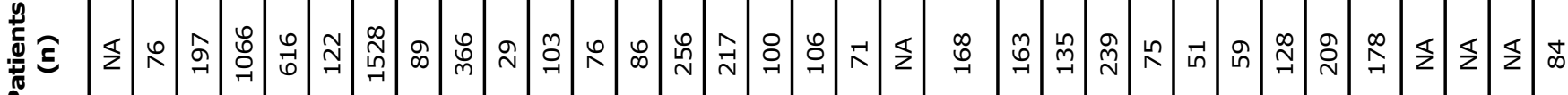

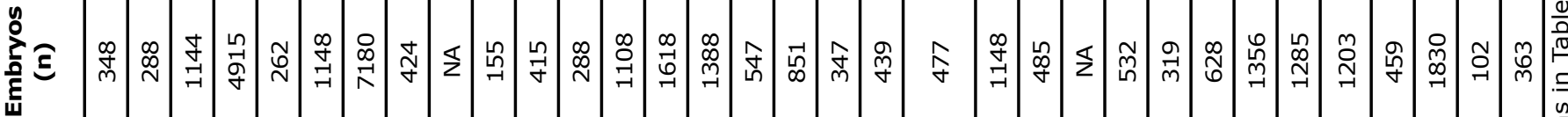

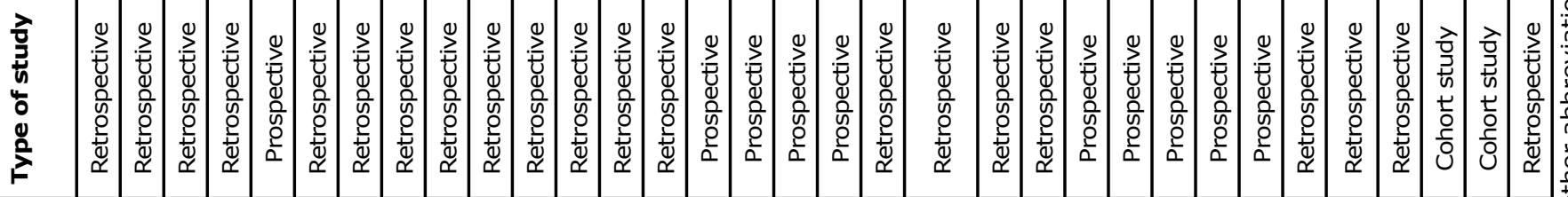

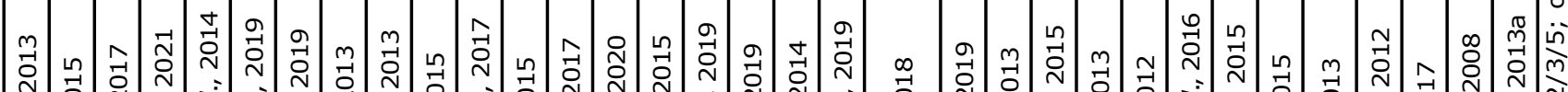

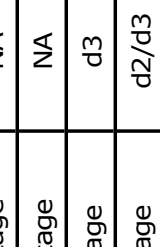




\section{Endometriosis}

Endometriosis is defined as the presence of endometrial glands and stroma cells growing outside the uterus (Burney \& Giudice, 2012). Endometriosis affects $10-15 \%$ of all women in reproductive age (Giudice \& Kao, 2004). It is associated with chronic pelvic pain and infertility (Parasar et al., 2017), and it is subdivided into four categories: stage I (minimal), stage II (mild), stage III (moderate) and stage IV (severe) (Johnson et al., 2017).

One study reported that endometriosis influences morphokinetic parameters without considering the severity of the disease; especially in early embryo stages (Freis et al., 2018). However, a deeper analysis associated with the endometriosis stages reported that patients with severe endometriosis reached t9 faster than patients with minimal or moderate endometriosis, as well as the control group (patients without endometriosis). Moreover, the synchronicity of the two blastomere divisions within the second cell cycle (s2) was faster in the endometriosis group than in women without endometriosis (Schenk et al., 2019).

On the other hand, a recent study concluded that embryos from endometriotic patients had different kinetics during cleavage stages, because they had a shorter cc1 and longer tPB, tPNa; as well as s2 than control group patients (Boynukalin et al., 2019).

\section{Smoking}

Its negative impact on fertility has been widely described in women and men, affecting gamete quality and embryo development (Waylen et al., 2009). Smoker women have a higher risk of fertilization failure and lower implantation rates (Gruber et al., 2008). Furthermore, smoking causes obstetric complications, such as miscarriages, preterm births and premature membrane rupture (Levis et al., 2014).

We know that smoking affects at least one of the embryological events in the early cleavage stage of development (Siristatidis et al., 2015). A study found that embryos from smokers are significantly slower during cleavage stages ( $t 3, t 4$ and $t 5)$, than those from nonsmokers; curiously, there are no kinetic differences between embryos from smokers and nonsmokers that stopped their development (Fréour et al., 2013).

\section{CULTURE MEDIA: SINGLE AND SEQUENTIAL MEDIA}

Embryos can be cultured in uninterrupted culture using a single medium throughout the $5 / 6$ days of culture or sequential media, where two media with different composition are used sequentially (Costa-Borges et al., 2016).

Studies with oocytes from donors and patients have not reported differences in morphokinetic parameters between single step media and sequential media in embryo cultures until days 3 or 5/6 (Basile et al., 2013; Costa-Borges et al., 2016).

On the other hand, a study using autologous oocytes suggested that embryos cultured in a single media have faster development from tPNf until t5 than those cultured in sequential media (Ciray et al., 2012); while a multicenter clinical trial reported a delay in $\mathrm{t} 7, \mathrm{t} 8$ in embryos cultured in single media (Hardarson et al., 2015).

Interestingly, besides the differences in morphokinetics, the studies did not find differences in implantation rate, ongoing pregnancy rates and live birth between the groups (Ciray et al., 2012; Basile et al., 2013; Hardarson et al., 2015; Costa-Borges et al., 2016). However, single media simplifies the logistics of an IVF laboratory, and the embryos can be assessed without disturbing culture conditions through the time-lapse system.

\section{FERTILIZATION TECHNIQUE}

Oocytes are inseminated using conventional in vitro fertilization (IVF) or Intracytoplasmic sperm injection (ICSI). When IVF is performed, some sperm selection processes are maintained in vitro. These processes are sperm penetration of the cumulus cells, zona pellucida interaction and fusion of the oolemma, whereas during ICSI a single sperm is injected into a mature oocyte.

These two processes are different, and it is not possible to determine exactly when fertilization occurs in IVF. Some time-lapse studies reported a faster development in embryos generated by ICSI than in IVF (Lemmen et al., 2008; Dal Canto et al., 2012; Kim et al., 2017). However, it is a consensus that tPNf can be used as starting point when IVF or ICSI are used as a fertilization method (Cruz et al., 2013; Bodri et al., 2015).

When tPNf was used as a starting point, there were any observed differences in the cleavage stage (early and late) between the IVF and the ICSI techniques (Cruz et al., 2013; Bodri et al., 2015), although one of them reported a faster development in the blastocyst stage in IVF- fertilized embryos (Bodri et al., 2015). This could be explained because when IVF is performed the semen characteristics are superior to those in ICSI (Cruz et al., 2013; Bodri et al., 2015). Under this evidence, confounding factors should also be considered when both techniques are compared.

\section{OXYGEN CONCENTRATION AND UNINTER- RUPTED CULTURE CONDITIONS}

Oxygen concentration differs in the female reproductive tract, and it decreases from the fallopian tubes towards the uterus. The concentration ranges from $5-7 \%$ to $2 \%$ ( $\mathrm{Ng}$ et al., 2018). Oxygen can influence embryo development. It is well documented that embryos cultured under lower oxygen concentration ( $5 \%$ ) have more cleavage, good quality and more embryos are cryopreserved, which improved embryo implantation compared to those embryos cultured under higher oxygen concentration (20\%) (Sciorio \& Smith, 2019; Van Montfoort et al., 2020). Similar results were also found in the TL-system. A study reported a low quality of embryos, a lower number of utilized embryos and delays in s3 when the embryos were cultured in high-oxygen concentration (20\%) (Kirkegaard et al., 2013b)

Additionally, in the TL-system, the embryos do not need to be removed from the incubator, this minimizes environmental disturbances caused by bench-top incubators. Interestingly, a study reported a higher live birth rate in embryos cultured in the TL-system, when compared to embryos cultured in high-quality $\mathrm{K}$-systems, both using $5 \%$ $\mathrm{O}_{2}$ (Kalleas et al., 2020).

\section{COLLAPSE}

Collapse is a separation of all or part of the trophectoderm (TE) cells from the zona pellucida (ZP) during blastocyst growth, the cells could be separated; when more than $50 \%$ form the inner side of the ZP (collapse or strong contraction) or less than $50 \%$ (weak contraction) (Marcos et al., 2015).

Blastocyst collapse is independent of the insemination technique (Sciorio et al. 2020a; b) and maternal age (Bodri et al., 2016; Gazzo et al., 2020). Whereas the relationship between collapse and embryo quality is arguable, because a study did not find a relation (Marcos et al., 2015), while two studies proposed a higher incidence of blastocyst collapse in poor quality embryos (Bodri et al., 2016; Sciorio et al., 2020b). 
Embryos at the blastocyst stage could collapse at least one time. However, not all the blastocyst collapses (Marcos et al., 2015; Bodri et al., 2016; Viñals Gonzalez et al., 2018; Sciorio et al., 2020a; b). Retrospectives studies in TL showed that embryos that collapse during their development have lower implantation and pregnancy rates, especially if they were multiple when compared to blastocysts that did not display this event, although there are no relations between collapse duration and decreased implantation rates (Marcos et al., 2015; Bodri et al., 2016; Viñals Gonzalez et al., 2018; Gazzo et al., 2020; Sciorio et al., 2020a;b).

Embryo collapse and aneuploidy has also been investigated. It is reported that collapses were predominantly present in aneuploid embryos; moreover, embryos affected with monosomies have lower numbers of collapses when compared with trisomy or complex aneuploidies (Viñals Gonzalez et al., 2018). Even if an euploid embryo has collapses, it has a lower live-birth rate (Harton et al., 2016).

According to morphokinetic parameters, embryos without collapse had a slow development during early stages ( $t 2, t 3, t 4$ and $t B$ ) compared to those blastocyst which underwent blastocyst collapse (Marcos et al., 2015); while other studies reported that collapsed embryos took longer to reach the blastocyst stage (Gazzo et al., 2020), and a delayed development during the blastocyst stage (Bodri et al., 2016).

\section{RE-EXPANSION IN THAWED EMBRYOS}

Freezing embryos is a common practice. It enables a single embryo transfer, genetics test or freeze all strategy for better endometrium preparation. During vitrification processes, embryos are dehydrated through the addition of cryoprotectants and, consequently, they shrunk. Immediately after warming, the embryos look collapsed, and need more time to recover their initial volume (re-expansion).

Blastocyst quality evaluation is difficult after the warming process. For that reason, post-warmed culture helps assess the vitrified/warmed blastocyst (Zhao et al., 2019). A study using the TL-system reported that re-expansion started as early as 10 minutes and can complete the re-expansion in 2 hours after warming (Ebner et al., 2017).

Embryos without re-expansion after the warming process have a significantly lower implantation rate when compared with the completely or partially re-expanded blastocyst (Desai et al., 2016; Coello et al., 2017; Ebner et al., 2017). In addition, after warming, the embryos can also have collapses, even more than once. However, it does not seem to affect implantation (Coello et al., 2017; Ebner et al., 2017). Shorter-duration re-expansion (from start to complete re-expansion) has been documented in those blastocysts that result in pregnancy in comparison to non-pregnant women (Ebner et al., 2017).

Furthermore, a predictive implantation model that evaluated morphology in post-warmed blastocyst has been proposed. The embryos were subdivided into four categories from $A$ to $D$. If the maximum area values were $>14,597 \mathrm{~mm}^{2}$, the blastocysts were categorized as $A$ or $\mathrm{B}$, depending on whether the initial area values were $>9,900 \mathrm{~mm}^{2}$ or $<9,900 \mathrm{~mm}^{2}$, respectively. Similarly, if the maximum area values were $<14,597 \mathrm{~mm}^{2}$, the blastocysts were categorized as C or D, depending on the initial area. They found that implantation was $47.3 \%, 43.7 \%, 32.8 \%$ and $14.2 \%$ for $A$ to $D$, respectively (Coello et al., 2017).

\section{ATYPICAL DYNAMIC EMBRYO BEHAVIORS RE- LATED TO LOWER IMPLANTATION}

Atypical dynamic embryo behaviors could happen during their early development, and are not maternal-age dependent (Athayde Wirka et al., 2014; Zhan et al., 2016; Yang et al., 2018). Embryos with anomalous divisions are more likely to arrest their development than embryos with normal divisions, especially during their first stages of development (Lagalla et al., 2017). Moreover, their embryo potential and implantation rates are adversely affected (Meseguer et al., 2011; Hlinka et al., 2012; Hur et al., 2018; Yang et al., 2018). These abnormal behaviors can only be visualized through continuous observation and subsequent time-lapse analysis.

Although, several atypical dynamic embryo behaviors have been described, two have shown to play a major role: Direct Cleavage (DC) and Reverse Cleavage (RC).

Direct Cleavage is defined as the second cell cycle being shorter than 5 hours, or more than 2 cells originated from a single cell division event. DC can occur during cleavage and their frequency is higher during the first cleaving periods (Fan et al., 2016); moreover, it could be present more than once (Zhan et al., 2016). It is noteworthy that DC in embryos, especially at earlier stages, strongly correlates with impaired blastocyst formation, implantation and clinical outcome (Rubio et al., 2012; Athayde Wirka et al., 2014; Fan et al., 2016; Zhan et al., 2016).

DC embryos are more often found during IVF cycles than ICSI cycles (Zhan et al., 2016), at higher percentages when testicular and epididymal sperm are used (Kahraman et al., 2020; Zhan et al., 2016). Additionally, DC embryos have 2.5 to 3.1 fold higher likelihood of a multinucleation incidence (Zhan et al., 2016).

Likewise, two retrospective studies suggest that DC embryos can undergo self-correction mechanisms while excluding some cells (with higher incidence of aneuploidies) during the compaction process. Therefore, DC embryos showed a similar euploid rate when compared to non-DC blastocysts on day 5 (Zhan et al., 2016)4. Nevertheless, this mechanism is significantly lower in older patients ( $>39$ years) (Lagalla et al., 2017).

Reverse Cleavage is defined as either blastomeres rejoining after complete separation, or the blastomere fails to separate. It could occur during the cleavage stage, with major incidence during the third cycle of the mitotic division (5 to 8 cells) (Liu et al., 2014). The mean time of occurrence reported was $46.07 \mathrm{~h}$ (Quera et al., 2014) and between 24 to 136h (Hickman et al., 2013).

In addition, $\mathrm{RC}$ affect the blastocyst stage development (Desai et al., 2018). Embryos with RC have significantly lower good-quality embryos on day 3 (Liu et al., 2014), and consequently a lower blastocyst formation rate (Yang et al., 2018). Furthermore, RC embryos implanted less than their counterparts (Liu et al., 2014), especially if two or more abnormal cleavages were present in a single embryo, increasing the likelihood of the embryo being aneuploid (Desai et al., 2018).

\section{PLOIDY}

A meta-analysis concluded that Time-lapse embryo monitoring may help predict the ploidy of embryos (Swain, 2013), even though other studies proposed that morphokinetics are not enough (Reignier et al., 2018); but it provides valuable information for embryo selection (Zaninovic et al., 2017).

Some studies did not find differences during the cleavage and blastocyst stages of embryo development between euploids and aneuploids (Stevens et al., 2012; Semeniuk et al., 2013; Yang et al., 2014) (Table 3). Conversely, others have reported a development delay in aneuploid embryos during cleavage and blastocyst stages (Table 3) (Davies et al., 2012; Campbell et al., 2013; Vera-Rodriguez et al., 2015; Chawla et al., 2015; Mumusoglu et al., 2017; Zhang et al., 2017; Huang et al., 2019). 


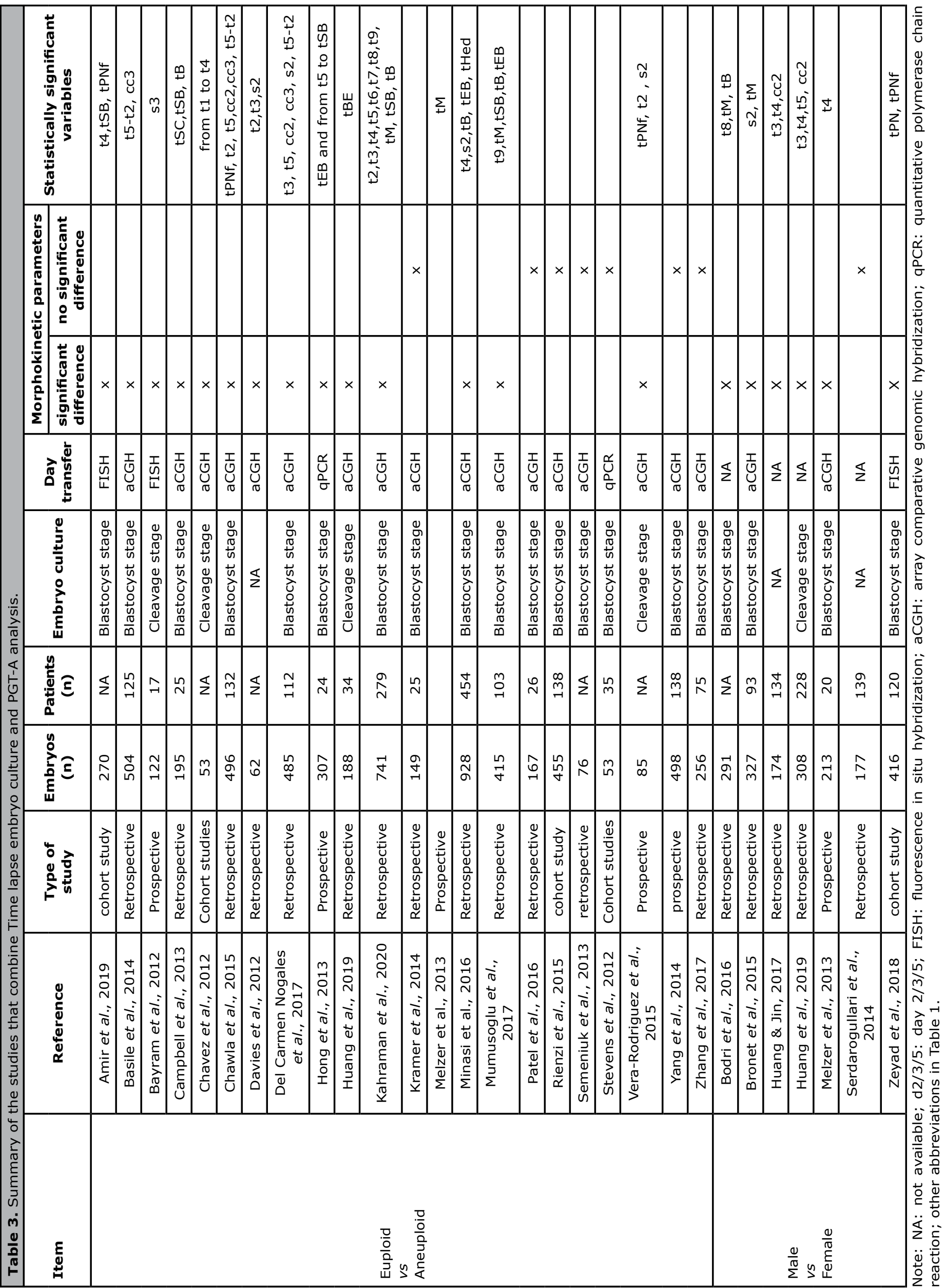


Similarly, a prospective study reported that chromosomally normal embryos display strict and tightly clustered cell cycle parameters up to the 4-cell stage (Chavez et al., 2012). Other studies found shorter stages in euploid embryos than aneuploid embryos: in s3 (Bayram et al., 2012), a shorter compaction (Melzer et al., 2013) and early cavitation from first cytokinesis and from t5 (Hong et al., 2013), a shorter cleavage $s 2$ and $t 4$ as well during the blastocyst stage tB, tEB and thed (Minasi et al., 2016), a faster development from t2 to blastocyst stage; however, these differences are not present in severe forms of male infertility (less than $1 \times 10^{6}$ spermatozoa $/ \mathrm{ml}$ ) (Kahraman et al., 2020).

In addition, a retrospective study reported that embryos with trisomy showed very similar kinetics to those of normal embryos, whereas embryos with monosomies fall between complex and trisomy embryos (Del Carmen Nogales et al., 2017). Furthermore, embryos with complex chromosomal abnormalities have the shortest division times ( $t 3, t 5, c c 2, c c 3, s 2$ and $t 5-t 2)$, which is strongly associated with $\mathrm{t} 3$ and $\mathrm{t} 5$ - $\mathrm{t} 2$ (time interval between the 2- and the 5-cell stage) (Del Carmen Nogales et al., 2017). Moreover, a study reported that unbalanced chromosomal translocation embryos showed a delay of t4, tSB and s2, and embryos with balanced translocation did not; even a delay in tPNf was seen in embryos with nonviable unbalanced chromosomal translocation, when compared to potentially viable embryos (Amir et al., 2019).

Likewise, there are models proposed to identify embryos more likely to be euploid, based on variables. Some studies have identified that $\mathrm{t} 5-\mathrm{t} 2, \mathrm{cc} 3, \mathrm{tSB}$ and $\mathrm{tB}$ are good predictor variables (Basile et al., 2014; Campbell et al., 2013); others have been more specific, a cc3 (t5-t3) $>10.00 \mathrm{~h}$ and t5-t2 > 20.00h (Chawla et al., 2015), and blastocyst initiation (tSB $>96.2 \mathrm{~h}$ ); progression to expanded blastocysts (tSB $>166 \mathrm{~h}$ ) and tEB- tSB $>13 \mathrm{~h}$ in aneuploid embryos (Desai et al., 2018) are morphokinetic parameters associated with aneuploidy.

On the other hand, other studies demonstrated that the models described above were unable to discriminate between euploid and aneuploid embryos (Kramer et al., 2014; Rienzi et al., 2015; Patel et al., 2016; Zhang et al., 2017).

\section{Sex}

A single study with 177 embryos reported that female embryos showed earlier cavitation than male embryos, but it did not reach statistical significance (Serdarogullari et al., 2014). However, studies with aCGH analysis found a faster development in male embryos. A single study found that male embryos tend towards a faster progression to t4 than female embryos, with 213 embryos included (Melzer et al., 2013); while a study with 327 embryos also found a faster development in male embryos. Hence, they proposed an algorithm based on s2 and tM that permits identifying embryos with higher probability of being female (Bronet et al., 2015). By contrast, a study evaluated 416 embryos through the FISH technique, and they reported that tPN is significantly faster in female than male embryos; whereas tPNf was significantly faster in male embryos; and the blastulation rate was significantly higher in female embryos (Zeyad et al., 2018).

As described above, a retrospective study based on 81 live births reported a significantly slower development for tB in male embryos than in female embryos (Bodri et al., 2016). Meanwhile, retrospectives studies reported t3, t4 and cc2 earlier in male embryos than those of female embryos (Huang \& Jin, 2017); as well as $t 3, t 4, t 5$ and cc2 (Huang et al., 2019). However, only t3 ( $<14 \mathrm{~h}$ ) was correlated with live birth sex (Huang et al., 2019).

\section{CONCLUSIONS}

Time Lapse provides valuable information and enormous potential to enhance our understanding of embryo development. Considerable knowledge has been accumulated and describes the morphokinetic dynamics during different stages in human embryos. It has been demonstrated that some patient characteristics and culture conditions modified this development pattern. There is a consensus that embryos generated from advanced maternal age have a slow development. Moreover, the current available data about smoking and high-oxygen concentration cultures are scarce, but it also demonstrated a slow development in both groups. On the contrary, any difference in morphokinetics has been described when IVF or ICSI was used as the fertilization method. Similar observations were found when the embryos were culture in single or sequential media.

On the other hand, the limited number of studies, the considerable differences in the study designs and patients' characteristics like BMI, PCOS, endometriosis, ploidy and gender made it difficult to draw a conclusion. Given this inconsistency and lack of evidence, more prospective studies and further randomized clinical trials are needed.

The association between morphokinetics and ART outcome has important implications in clinical results; where two morphokinetic events have the potential to predict embryo implantation: blastocyst collapse-re-expansion and direct-reverse cleavage seems to have a strong impact on clinical outcomes.

\section{ACKNOWLEDGEMENTS}

The authors would like to thank Marcos Meseguer Escrivá from IVIRMA Valencia for his evaluation, critical reading and comments on the final project of Silvana Márquez, on which this manuscript is based.

\section{Authors' contributions}

SM; draft the manuscript. LG; draft and review the manuscript. $\mathrm{LNH}$; review the manuscript.

\section{CONFLICT OF INTEREST}

The authors declare no conflict of interest.

\section{Corresponding author:}

Silvana Márquez

Clínica Concebir.

San Isidro. Lima. Perú.

E-mail: silvana.marquez.h@gmail.com

\section{REFERENCES}

Akarsu S, Gode F, Isik AZ, Celenk H, Tamer FB, Erkilinc $\mathrm{S}$. Comparison of the morphokinetic parameters of embryos according to ovarian reserve in IVF cycles. Gynecol Endocrinol. 2017;33:733-6. PMID: 28412866 DOI: $10.1080 / 09513590.2017 .1312327$

Amir H, Barbash-Hazan S, Kalma Y, Frumkin T, Malcov M, Samara N, Hasson J, Reches A, Azem F, Ben-Yosef D. Timelapse imaging reveals delayed development of embryos carrying unbalanced chromosomal translocations. J Assist Reprod Genet. 2019;36:315-24. PMID: 30421343 DOI: $10.1007 / \mathrm{s} 10815-018-1361-8$

Armstrong S, Bhide P, Jordan V, Pacey A, Farquhar C. Time-lapse systems for embryo incubation and assessment in assisted reproduction. Cochrane Database Syst Rev. 2018;5:CD011320. PMID: 29800485 DOI: 10.1002/14651858.CD011320.pub3 
Athayde Wirka K, Chen AA, Conaghan J, Ivani K, Gvakharia M, Behr B, Suraj V, Tan L, Shen S. Atypical embryo phenotypes identified by time-lapse microscopy: high prevalence and association with embryo development. Fertil Steril. 2014;101:1637-48.e1-5. PMID: 24726214 DOI: 10.1016/j.fertnstert.2014.02.050

Bartolacci A, Buratini J, Moutier C, Guglielmo MC, Novara PV, Brambillasca F, Renzini MM, Dal Canto M. Maternal body mass index affects embryo morphokinetics: a time-lapse study. J Assist Reprod Genet. 2019;36:1109-16. PMID: 31062218 DOI: $10.1007 / \mathrm{s} 10815-019-01456-3$

Basile N, Morbeck D, García-Velasco J, Bronet F, Meseguer M. Type of culture media does not affect embryo kinetics: a time-lapse analysis of sibling oocytes. Hum Reprod. 2013;28:634-41. PMID: 23315059 DOI: 10.1093/humrep/des462

Basile N, Nogales Mdel C, Bronet F, Florensa M, Riqueiros M, Rodrigo L, García-Velasco J, Meseguer M. Increasing the probability of selecting chromosomally normal embryos by time-lapse morphokinetics analysis. Fertil Steril. 2014;101:699-704. PMID: 24424365 DOI: 10.1016/j. fertnstert.2013.12.005

Bayram A, Ciray HN, Sahin O, Okutman-Emonts O, Bahceci M. Comparison of morphokinetic parameters between euploid and aneuploid embryos by time-lapse monitoring. Hum Reprod. 2012;27:ii103-5.

Bellver J, Ayllón Y, Ferrando M, Melo M, Goyri E, Pellicer A, Remohí J, Meseguer M. Female obesity impairs in vitro fertilization outcome without affecting embryo quality. Fertil Steril. 2010;93:447-54. PMID: 19171335 DOI: 10.1016/j. fertnstert.2008.12.032

Bellver J, Mifsud A, Grau N, Privitera L, Meseguer M. Similar morphokinetic patterns in embryos derived from obese and normoweight infertile women: a time-lapse study. Hum Reprod. 2013;28:794-800. PMID: 23293223 DOI: $10.1093 /$ humrep/des438

Bodri D, Sugimoto T, Serna JY, Kondo M, Kato R, Kawachiya $\mathrm{S}$, Matsumoto $\mathrm{T}$. Influence of different oocyte insemination techniques on early and late morphokinetic parameters: retrospective analysis of 500 time-lapse monitored blastocysts. Fertil Steril. 2015;104:1175-81.e1-2. PMID: 26307686 DOI: 10.1016/j.fertnstert.2015.07.1164

Bodri D, Sugimoto T, Yao Serna J, Kawachiya S, Kato R, Matsumoto T. Blastocyst collapse is not an independent predictor of reduced live birth: a time-lapse study. Fertil Steril. 2016;105:1476-83.e3. PMID: 26940789 DOI: 10.1016/j.fertnstert.2016.02.014

Boynukalin FK, Serdarogullari M, Gultomruk M, Coban $\mathrm{O}$, Findikli N, Bahceci $\mathrm{M}$. The impact of endometriosis on early embryo morphokinetics: a case-control study. Syst Biol Reprod Med. 2019;65:250-7. PMID: 30741013 DOI: 10.1080/19396368.2019.1573275

Bronet F, Nogales MC, Martínez E, Ariza M, Rubio C, García-Velasco JA, Meseguer M. Is there a relationship between time-lapse parameters and embryo sex? Fertil Steril. 2015;103:396-401.e2. PMID: 25487751 DOI: 10.1016/j. fertnstert.2014.10.050
Burney RO, Giudice LC. Pathogenesis and pathophysiology of endometriosis. Fertil Steril. 2012;98:511-9. PMID: 22819144 DOI: $10.1016 /$ j.fertnstert.2012.06.029

Campbell A, Fishel S, Bowman N, Duffy S, Sedler M, Hickman CF. Modelling a risk classification of aneuploidy in human embryos using non-invasive morphokinetics. Reprod Biomed Online. 2013;26:477-85. PMID: 23518033 DOI: 10.1016/j.rbmo.2013.02.006

Chappell NR, Shah J, Peavey M, Yang L, Sangi-Haghpeykar H, Gibbons WE, Blesson CS. Embryos from polycystic ovary syndrome (PCOS) patients reach morula stage faster than age and body mass index (BMI) matched controls. Fertil Steril. 2017;108:E245. DOI: 10.1016/j.fertnstert.2017.07.736

Chappell NR, Barsky M, Shah J, Peavey M, Yang L, Sangi-Haghpeykar H, Gibbons W, Blesson CS. Embryos from polycystic ovary syndrome patients with hyperandrogenemia reach morula stage faster than controls. F S Rep. 2020;1:125-32. PMID: 34223228 DOI: 10.1016/j. xfre.2020.05.006

Chavez SL, Loewke KE, Han J, Moussavi F, Colls P, Munne S, Behr B, Reijo Pera RA. Dynamic blastomere behaviour reflects human embryo ploidy by the four-cell stage. Nat Commun. 2012;3:1251. PMID: 23212380 DOI: $10.1038 /$ ncomms 2249

Chawla M, Fakih M, Shunnar A, Bayram A, Hellani A, Perumal V, Divakaran J, Budak E. Morphokinetic analysis of cleavage stage embryos and its relationship to aneuploidy in a retrospective time-lapse imaging study. J Assist Reprod Genet. 2015;32:69-75. PMID: 25395178 DOI: $10.1007 / \mathrm{s} 10815-014-0372-3$

Chen M, Wei S, Hu J, Yuan J, Liu F. Does time-lapse imaging have favorable results for embryo incubation and selection compared with conventional methods in clinical in vitro fertilization? A meta-analysis and systematic review of randomized controlled trials. PLoS One. 2017;12:e0178720. PMID: 28570713 DOI: $10.1371 /$ journal.pone. 0178720

Ciray HN, Aksoy T, Goktas C, Ozturk B, Bahceci M. Timelapse evaluation of human embryo development in single versus sequential culture media--a sibling oocyte study. J Assist Reprod Genet. 2012;29:891-900. PMID: 22714134 DOI: $10.1007 / \mathrm{s} 10815-012-9818-7$

Coello A, Meseguer M, Galán A, Alegre L, Remohí J, Cobo A. Analysis of the morphological dynamics of blastocysts after vitrification/warming: defining new predictive variables of implantation. Fertil Steril. 2017;108:659-66.e4. PMID: 28863936 DOI: 10.1016/j.fertnstert.2017.07.1157

Costa-Borges N, Bellés M, Meseguer M, Galliano D, Ballesteros A, Calderón G. Blastocyst development in single medium with or without renewal on day 3: a prospective cohort study on sibling donor oocytes in a time-lapse incubator. Fertil Steril. 2016;105:707-13. PMID: 26690010 DOI: $10.1016 /$ j.fertnstert.2015.11.038

Cruz M, Garrido N, Gadea B, Muñoz M, Pérez-Cano I, Meseguer $M$. Oocyte insemination techniques are related to alterations of embryo developmental timing in an oocyte donation model. Reprod Biomed Online. 2013;27:367-75. PMID: 23953584 DOI: 10.1016/j.rbmo.2013.06.017 
Dal Canto M, Coticchio G, Mignini Renzini M, De Ponti E, Novara PV, Brambillasca F, Comi R, Fadini R. Cleavage kinetics analysis of human embryos predicts development to blastocyst and implantation. Reprod Biomed Online. 2012;25:474-80. PMID: 22995750 DOI: $10.1016 / \mathrm{j}$. rbmo.2012.07.016

Dal Canto M, Bartolacci A, Turchi D, Pignataro D, Lain M, De Ponti E, Brigante C, Mignini Renzini M, Buratini J. Faster fertilization and cleavage kinetics reflect competence to achieve a live birth after intracytoplasmic sperm injection, but this association fades with maternal age. Fertil Steril. 2021;115:665-72. PMID: 32888678 DOI: 10.1016/j.fertnstert.2020.06.023

Davies S, Christopikou D, Tsorva E, Karagianni A, Handyside $\mathrm{AH}$, Mastrominas M. Delayed cleavage divisions and a prolonged transition between 2- and 4-cell stages in embryos identified as aneuploid at the 8-cell stage by array $\mathrm{CGH}$. Hum Reprod. 2012;27:ii84-6.

Del Carmen Nogales M, Bronet F, Basile N, Martínez EM, Liñán $A$, Rodrigo $L$, Meseguer $M$. Type of chromosome abnormality affects embryo morphology dynamics. Fertil Steril. 2017;107:229-35.e2. PMID: 27816230 DOI: 10.1016/j.fertnstert.2016.09.019

Desai N, Ploskonka S, Goodman L, Attaran M, Goldberg JM, Austin C, Falcone T. Delayed blastulation, multinucleation, and expansion grade are independently associated with live-birth rates in frozen blastocyst transfer cycles. Fertil Steril. 2016;106:1370-8. PMID: 27565255 DOI: 10.1016/j.fertnstert.2016.07.1095

Desai N, Goldberg JM, Austin C, Falcone T. Are cleavage anomalies, multinucleation, or specific cell cycle kinetics observed with time-lapse imaging predictive of embryo developmental capacity or ploidy? Fertil Steril. 2018;109:665-74. PMID: 29452698 DOI: $10.1016 / j$.fertnstert.2017.12.025

Ebner T, Oppelt P, Radler E, Allerstorfer C, Habelsberger A, Mayer RB, Shebl O. Morphokinetics of vitrified and warmed blastocysts predicts implantation potential. J Assist Reprod Genet. 2017;34:239-44. PMID: 27943109 DOI: 10.1007/ s10815-016-0855-5

Fan YL, Han SB, Wu LH, Wang YP, Huang GN. Abnormally cleaving embryos are able to produce live births: a timelapse study. J Assist Reprod Genet. 2016;33:379-85. PMID: 26749387 DOI: 10.1007/s10815-015-0632-x

Freis A, Dietrich JE, Binder M, Holschbach V, Strowitzki T, Germeyer A. Relative Morphokinetics Assessed by TimeLapse Imaging Are Altered in Embryos From Patients With Endometriosis. Reprod Sci. 2018;25:1279-85. PMID: 29141509 DOI: $10.1177 / 1933719117741373$

Fréour T, Dessolle L, Lammers J, Lattes S, Barrière P. Comparison of embryo morphokinetics after in vitro fertilization-intracytoplasmic sperm injection in smoking and nonsmoking women. Fertil Steril. 2013;99:1944-50. PMID: 23465820 DOI: 10.1016/j.fertnstert.2013.01.136

Gardner DK, Meseguer M, Rubio C, Treff NR. Diagnosis of human preimplantation embryo viability. Hum Reprod Update. 2015;21:727-47. PMID: 25567750 DOI: 10.1093/ humupd/dmu064
Gazzo E, Peña F, Valdéz F, Chung A, Velit M, Ascenzo M, Escudero $E$. Blastocyst contractions are strongly related with aneuploidy, lower implantation rates, and slow-cleaving embryos: a time lapse study. JBRA Assist Reprod. 2020;24:77-81. PMID: 31524340 DOI: 10.5935/1518-0557.20190053

Gesink Law DC, Maclehose RF, Longnecker MP. Obesity and time to pregnancy. Hum Reprod. 2007;22:414-20. PMID: 17095518 DOI: $10.1093 /$ humrep/del400

Giudice LC, Kao LC. Endometriosis. Lancet. 2004;364:1789-99. PMID: 15541453 DOI: 10.1016/ S0140-6736(04)17403-5

Grøndahl ML, Christiansen SL, Kesmodel US, Agerholm IE, Lemmen JG, Lundstrøm P, Bogstad J, Raaschou-Jensen M, Ladelund S. Effect of women's age on embryo morphology, cleavage rate and competence-A multicenter cohort study. PLoS One. 2017;12:e0172456. PMID: 28422964 DOI: 10.1371/journal. pone.0172456

Gruber I, Just A, Birner M, Lösch A. Effect of a woman's smoking status on oocyte, zygote, and day 3 pre-embryo quality in in vitro fertilization and embryo transfer program. Fertil Steril. 2008;90:1249-52. PMID: 17905237 DOI: $10.1016 /$ j.fertnstert.2007.06.108

Gryshchenko MG, Pravdyuk AI, Parashchyuk VY. Analysis of factors influencing morphokinetic characteristics of embryos in ART cycles. Gynecol Endocrinol. 2014;30:6-8. PMID: 25200818 DOI: 10.3109/09513590.2014.945763

Hardarson T, Bungum M, Conaghan J, Meintjes M, Chantilis SJ, Molnar L, Gunnarsson K, Wikland M. Noninferiority, randomized, controlled trial comparing embryo development using media developed for sequential or undisturbed culture in a time-lapse setup. Fertil Steril. 2015;104:1452-9.e1-4. PMID: 26409153 DOI: 10.1016/j. fertnstert.2015.08.037

Harton G, Tan L, Chian M, Suraj V, Shen S, Larman MG. Euploid blastocysts that experience more collapses are less likely to result in live birth: a quantitative and automated analysis of time-lapse cinematography. Hum Reprod. 2016;31:i95.

Hickman CFL, Lennon J, Cook C, Perez MJ, Mania A, Lavery $S$. Factors affecting morphokinetics: sperm origin, maternal age and ploidy. Fertil Steril. 2013;100:S6-7. DOI: 10.1016/j.fertnstert.2013.07.142

Hlinka D, Kal'atová B, Uhrinová I, Dolinská S, Rutarová J, Rezáčová J, Lazarovská S, Dudáš M. Time-lapse cleavage rating predicts human embryo viability. Physiol Res. 2012;61:513-25. PMID: 22881225 DOI: 10.33549/physiolres.932287

Hong KH, Forman EJ, Prodoehl A, Upham KM, Treff NR, Scott RT Jr. Early times to cavitation are associated with a reduced prevalence of aneuploidy in embryos cultured to the blastocyst stage: a prospective blinded morphokinetic study. Fertil Steril. 2013;100:S382. DOI: 10.1016/j.fertnstert.2013.07.723

Huang B, Jin L. Human embryo development characteristics may affect live birth sex ratio: a time-lapse study. Fertil Steril. 2017;108:E164. DOI: 10.1016/j.fertnstert.2017.07.494 
Huang B, Ren X, Zhu L, Wu L, Tan H, Guo N, Wei Y, Hu J, Liu $Q$, Chen W, Liu J, Li D, Liao S, Jin L. Is differences in embryo morphokinetic development significantly associated with human embryo sex?. Biol Reprod. 2019;100:618-23. PMID: 30371742 DOI: 10.1093/biolre/ioy229

Hur YS, Ryu EK, Hyun CS, Yang SH, Yoon SH, Lim KS, Lee WD, Lim JH. Retrospective study of single vitrified-warmed blastocyst transfer cycles according to the presence of morphokinetic variables. Clin Exp Reprod Med. 2018;45:52-5. PMID: 29662827 DOI: $10.5653 /$ cerm.2018.45.1.52

Johnson NP, Hummelshoj L, Adamson GD, Keckstein J, Taylor HS, Abrao MS, Bush D, Kiesel L, Tamimi R, SharpeTimms KL, Rombauts L, Giudice LC; World Endometriosis Society Sao Paulo Consortium. World Endometriosis Society consensus on the classification of endometriosis. Hum Reprod. 2017;32:315-24. PMID: 27920089 DOI: 10.1093/ humrep/dew293

Kahraman S, Sahin $Y$, Yelke $H$, Kumtepe $Y$, Tufekci MA, Yapan CC, Yesil M, Cetinkaya M. High rates of aneuploidy, mosaicism and abnormal morphokinetic development in cases with low sperm concentration. J Assist Reprod Genet. 2020;37:629-40. PMID: 31901112 DOI: 10.1007/ s10815-019-01673-w

Kalleas D, McEvoy K, Horne G, Roberts SA, Brison DR. Live birth rate following undisturbed embryo culture at low oxygen in a time-lapse incubator compared to a high-quality benchtop incubator. Hum Fertil (Cam). 2020:1-7. Epub ahead of print. PMID: 32098536 DOI: $10.1080 / 14647273.2020 .1729423$

Kim $\mathrm{HJ}$, Yoon $\mathrm{HJ}$, Jang JM, Lee WD, Yoon $\mathrm{SH}$, Lim JH. Evaluation of human embryo development in in vitro fertilizationand intracytoplasmic sperm injection-fertilized oocytes: A time-lapse study. Clin Exp Reprod Med. 2017;44:90-5. PMID: 28795048 DOI: $10.5653 /$ cerm.2017.44.2.90

Kirkegaard K, Hindkjaer JJ, Ingerslev HJ. Effect of oxygen concentration on human embryo development evaluated by time-lapse monitoring. Fertil Steril. 2013a;99:738-44.e4. PMID: 23245683 DOI: $10.1016 /$ j.fertnstert.2012.11.028

Kirkegaard K, Kesmodel US, Hindkjaer JJ, Ingerslev $\mathrm{HJ}$. Time-lapse parameters as predictors of blastocyst development and pregnancy outcome in embryos from good prognosis patients: a prospective cohort study. Hum Reprod. 2013b;28:2643-51. PMID: 23900207 DOI: 10.1093/ humrep/det300

Kramer YG, Kofinas JD, Melzer K, Noyes N, McCaffrey C, Buldo-Licciardi J, McCulloh DH, Grifo JA. Assessing morphokinetic parameters via time lapse microscopy (TLM) to predict euploidy: are aneuploidy risk classification models universal? J Assist Reprod Genet. 2014;31:1231-42. PMID: 24962789 DOI: 10.1007/s10815-014-0285-1

Krizanovská K, Ulcová-Gallová Z, Bouse V, Rokyta Z. Hmotnost a poruchy reprodukce [Obesity and reproductive disorders]. Sb Lek. 2002;103:517-26. Czech. PMID: 12688167

Lagalla C, Tarozzi N, Sciajno R, Wells D, Di Santo M, Nadalini M, Distratis V, Borini A. Embryos with morphokinetic abnormalities may develop into euploid blastocysts. Reprod Biomed Online. 2017;34:137-46. PMID: 27938863 DOI: $10.1016 /$ j.rbmo.2016.11.008
Lammers J, Freour T, Splingart C, Barriere P. Effect of female underweight on embryo morphokinetic using timelapse. Hum Reprod. 2013;28:P-085. DOI: 10.1016/j. rbmo.2014.01.009

Leary C, Leese HJ, Sturmey RG. Human embryos from overweight and obese women display phenotypic and metabolic abnormalities. Hum Reprod. 2015;30:122-32. PMID: 25391239 DOI: 10.1093/humrep/deu276

Lemmen JG, Agerholm I, Ziebe S. Kinetic markers of human embryo quality using time-lapse recordings of IVF/ICSI-fertilized oocytes. Reprod Biomed Online. 2008;17:385-91. PMID: 18765009 DOI: $10.1016 / S 1472-$ $6483(10) 60222-2$

Levis DM, Stone-Wiggins B, O'Hegarty M, Tong VT, Polen $\mathrm{KN}$, Cassell CH, Council M. Women's perspectives on smoking and pregnancy and graphic warning labels. Am J Health Behav. 2014;38:755-64. PMID: 24933145 DOI: 10.5993/ AJHB.38.5.13

Liu Y, Chapple V, Roberts P, Matson P. Prevalence, consequence, and significance of reverse cleavage by human embryos viewed with the use of the Embryoscope timelapse video system. Fertil Steril. 2014;102:1295-300.e2. PMID: 25225070 DOI: 10.1016/j.fertnstert.2014.07.1235

Ludwig M, Schöpper B, Al-Hasani S, Diedrich K. Clinical use of a pronuclear stage score following intracytoplasmic sperm injection: impact on pregnancy rates under the conditions of the German embryo protection law. Hum Reprod. 2000;15:325-9. PMID: 10655303 DOI: 10.1093/ humrep/15.2.325

Marcos J, Pérez-Albalá S, Mifsud A, Molla M, Landeras J, Meseguer $\mathrm{M}$. Collapse of blastocysts is strongly related to lower implantation success: a time-lapse study. Hum Reprod. 2015;30:2501-8. PMID: 26355116 DOI: 10.1093/ humrep/dev216

Melzer KE, Noyes N, Hodes-Wertz B, McCulloh D, Munne $\mathrm{S}$, Grifo JA. How well do morphokinetic (MK) parameters and time-lapse microscopy (TLM) predict euploidy? a pilot study of TLM with trophectoderm (TE) biopsy with array comparative genomic hybridization (aCGH). Fertil Steril. 2013;100:S209. DOI: 10.1016/j.fertnstert.2013.07.1387

Meseguer M, Herrero J, Tejera A, Hilligsøe KM, Ramsing NB, Remohí J. The use of morphokinetics as a predictor of embryo implantation. Hum Reprod. 2011;26:2658-71. PMID: 21828117 DOI: 10.1093/humrep/der256

Minasi MG, Colasante A, Riccio T, Ruberti A, Casciani V, Scarselli F, Spinella F, Fiorentino F, Varricchio MT, Greco E. Correlation between aneuploidy, standard morphology evaluation and morphokinetic development in 1730 biopsied blastocysts: a consecutive case series study. Hum Reprod. 2016;31:2245-54. PMID: 27591227 DOI: 10.1093/ humrep/dew183

Mumusoglu S, Yarali I, Bozdag G, Ozdemir P, Polat M, Sokmensuer LK, Yarali H. Time-lapse morphokinetic assessment has low to moderate ability to predict euploidy when patient- and ovarian stimulation-related factors are taken into account with the use of clustered data analysis. Fertil Steril. 2017;107:413-21.e4. PMID: 27939508 DOI: 10.1016/j.fertnstert.2016.11.005 
Navot D, Bergh PA, Williams MA, Garrisi GJ, Guzman I, Sandler B, Grunfeld L. Poor oocyte quality rather than implantation failure as a cause of age-related decline in female fertility. Lancet. 1991;337:1375-7.

$\mathrm{Ng}$ KYB, Mingels $\mathrm{R}$, Morgan $\mathrm{H}$, Macklon $\mathrm{N}$, Cheong $\mathrm{Y}$. In vivo oxygen, temperature and $\mathrm{pH}$ dynamics in the female reproductive tract and their importance in human conception: a systematic review. Hum Reprod Update. 2018;24:15-34. PMID: 29077897 DOI: 10.1093/humupd/dmx028

Parasar P, Ozcan P, Terry KL. Endometriosis: Epidemiology, Diagnosis and Clinical Management. Curr Obstet Gynecol Rep. 2017;6:34-41. PMID: 29276652 DOI: 10.1007/ s13669-017-0187-1

Patel DV, Shah PB, Kotdawala AP, Herrero J, Rubio I, Banker MR. Morphokinetic behavior of euploid and aneuploid embryos analyzed by time-lapse in embryoscope. J Hum Reprod Sci. 2016;9:112-8. PMID: 27382237 DOI: $10.4103 / 0974-1208.183511$

Payne D, Flaherty SP, Barry MF, Matthews CD. Preliminary observations on polar body extrusion and pronuclear formation in human oocytes using time-lapse video cinematography. Hum Reprod. 1997;12:532-41. PMID: 9130755 DOI: $10.1093 /$ humrep/12.3.532

Pribenszky C, Nilselid AM, Montag M. Time-lapse culture with morphokinetic embryo selection improves pregnancy and live birth chances and reduces early pregnancy loss: a meta-analysis. Reprod Biomed Online. 2017;35:511-20. PMID: 28736152 DOI: 10.1016/j.rbmo.2017.06.022

Quera M, Florensa M, Esbert M. Frequency and impact on embryo development of reverse cleavage in human embryos. Reprod Biomed Online. 2014:28:S14. DOI: 10.1016/ S1472-6483(14)50030-2

Reignier A, Lammers J, Barriere P, Freour T. Can time-lapse parameters predict embryo ploidy? A systematic review. Reprod Biomed Online. 2018;36:380-7. PMID: 29398421 DOI: $10.1016 /$ j.rbmo.2018.01.001

Rienzi L, Capalbo A, Stoppa M, Romano S, Maggiulli R, Albricci L, Scarica C, Farcomeni A, Vajta G, Ubaldi FM. No evidence of association between blastocyst aneuploidy and morphokinetic assessment in a selected population of poor-prognosis patients: a longitudinal cohort study. Reprod Biomed Online. 2015;30:57-66. PMID: 25458852 DOI: $10.1016 /$ j.rbmo.2014.09.012

Rittenberg V, Seshadri S, Sunkara SK, Sobaleva S, OtengNtim E, El-Toukhy T. Effect of body mass index on IVF treatment outcome: an updated systematic review and meta-analysis. Reprod Biomed Online. 2011;23:421-39. PMID: 21885344 DOI: 10.1016/j.rbmo.2011.06.018

Rubio I, Kuhlmann R, Agerholm I, Kirk J, Herrero J, Escribá MJ, Bellver J, Meseguer M. Limited implantation success of direct-cleaved human zygotes: a time-lapse study. Fertil Steril. 2012;98:1458-63. PMID: 22925687 DOI: 10.1016/j.fertnstert.2012.07.1135

Sakkas D, Shoukir Y, Chardonnens D, Bianchi PG, Campana A. Early cleavage of human embryos to the two-cell stage after intracytoplasmic sperm injection as an indicator of embryo viability. Hum Reprod. 1998;13:182-7. PMID: 9512254 DOI: 10.1093/humrep/13.1.182
Schenk M, Kröpfl JM, Hörmann-Kröpfl M, Weiss G. Endometriosis accelerates synchronization of early embryo cell divisions but does not change morphokinetic dynamics in endometriosis patients. PLOS One. 2019;14:e0220529. PMID: 31369616 DOI: 10.1371/journal.pone.0220529

Sciorio R, Smith GD. Embryo culture at a reduced oxygen concentration of 5\%: a mini review. Zygote. 2019;27:35561. PMID: 31544720 DOI: 10.1017/S0967199419000522

Sciorio R, Thong KJ, Pickering SJ. Spontaneous blastocyst collapse as an embryo marker of low pregnancy outcome: A Time-Lapse study. JBRA Assist Reprod. 2020a;24:34-40. PMID: 31397550 DOI: 10.5935/1518-0557.20190044

Sciorio R, Herrer Saura R, Thong KJ, Esbert Algam M, Pickering SJ, Meseguer M. Blastocyst collapse as an embryo marker of low implantation potential: a time-lapse multicentre study. Zygote. 2020b;1-9. Epub ahead of print. DOI: $10.5935 / 1518-0557.20190044$

Scott L, Alvero R, Leondires M, Miller B. The morphology of human pronuclear embryos is positively related to blastocyst development and implantation. Hum Reprod. 2000;15:2394403. PMID: 11056141 DOI: 10.1093/humrep/15.11.2394

Semeniuk L, Mazur P, Mikitenko D, Nagorny V, Zukin V. Time-lapse and $\mathrm{aCGH}$, Is There Any Connection between Ploidy and Embryo Cleavage Timing on Early Stages of Embryo Development? Fertil Steril. 2013;99:S6. DOI: 10.1016/j.fertnstert.2013.01.009

Serdarogullari M, Findikli N, Goktas C, Sahin O, Ulug U, Yagmur E, Bahceci M. Comparison of gender-specific human embryo development characteristics by time-lapse technology. Reprod Biomed Online. 2014;29:193-9. PMID: 24925308 DOI: $10.1016 /$ j.rbmo.2014.03.026

Shah DK, Missmer SA, Berry KF, Racowsky C, Ginsburg ES. Effect of obesity on oocyte and embryo quality in women undergoing in vitro fertilization. Obstet Gynecol. 2011;118:63-70. PMID: 21691164 DOI: 10.1097/ AOG.0b013e31821fd360

Silva E, Hixon B, Katz-Jaffe M, Stevens JM, Schoolcraft WB, Krisher RL. The impact of maternal BMI on embryo kinetics and development is dependent upon maternal age. Fertil Steril. 2015;104:E217-8. DOI: 10.1016/j.fertnstert.2015.07.685

Siristatidis C, Komitopoulou MA, Makris A, Sialakouma A, Botzaki M, Mastorakos G, Salamalekis G, Bettocchi S, Palmer GA. Morphokinetic parameters of early embryo development via time lapse monitoring and their effect on embryo selection and ICSI outcomes: a prospective cohort study. J Assist Reprod Genet. 2015;32:563-70. PMID: 25617087 DOI: $10.1007 / \mathrm{s} 10815-015-0436-\mathrm{z}$

Stevens J, Rawlins M, Janesch A, Treff N, Schoolcraft WB, Katz-Jaffe MG. Time lapse observation of embryo development identifies later stage morphology based parameters associated with blastocyst quality but not chromosome constitution. Fertil Steril. 2012;98:S30. DOI: 10.1016/j.fertnstert.2012.07.112

Sundvall L, Kirkegaard K, Ingerslev HJ, Knudsen UB. Unaltered timing of embryo development in women with polycystic ovarian syndrome (PCOS): a time-lapse study. J Assist Reprod Genet. 2015;32:1031-42. PMID: 25925351 DOI: $10.1007 / \mathrm{s} 10815-015-0488-0$ 
Swain JE. Could time-lapse embryo imaging reduce the need for biopsy and PGS? J Assist Reprod Genet. 2013;30:1081-90. PMID: 23842747 DOI: 10.1007/ s10815-013-0048-4

Tabibnejad N, Sheikhha MH, Ghasemi N, Fesahat F, Soleimani M, Aflatoonian A. Association between early embryo morphokinetics plus cumulus cell gene expression and assisted reproduction outcomes in polycystic ovary syndrome women. Reprod Biomed Online. 2019;38:139-51. PMID: 30593440 DOI: 10.1016/j.rbmo.2018.10.010

Tam Le M, Van Nguyen T, Thanh Nguyen T, Thanh Thi Nguyen T, An Thi Nguyen T, Huy Vu Nguyen $Q$, Thanh Cao N. Does polycystic ovary syndrome affect morphokinetics or abnormalities in early embryonic development? Eur J Obstet Gynecol Reprod Biol X. 2019;3:100045. PMID: 31403129 DOI: $10.1016 /$ j.eurox.2019.100045

Van Montfoort APA, Arts EGJM, Wijnandts L, Sluijmer A, Pelinck MJ, Land JA, Van Echten-Arends J. Reduced oxygen concentration during human IVF culture improves embryo utilization and cumulative pregnancy rates per cycle. Hum Reprod Open. 2020;2020: hoz036.

Vera-Rodriguez M, Chavez SL, Rubio C, Reijo Pera RA, Simon C. Prediction model for aneuploidy in early human embryo development revealed by single-cell analysis. Nat Commun. 2015;6:7601. PMID: 26151134 DOI: 10.1038/ncomms8601

Viñals Gonzalez X, Odia R, Cawood S, Gaunt M, Saab W, Seshadri S, Serhal P. Contraction behaviour reduces embryo competence in high-quality euploid blastocysts. J Assist Reprod Genet. 2018;35:1509-17. PMID: 29980895 DOI: $10.1007 / \mathrm{s} 10815-018-1246-\mathrm{x}$

Warshaviak M, Kalma Y, Carmon A, Samara N, Dviri M, Azem F, Ben-Yosef D. The Effect of Advanced Maternal Age on Embryo Morphokinetics. Front Endocrinol (Lausanne). 2019;10:686. PMID: 31708867 DOI: 10.3389/fendo. 2019.00686

Waylen AL, Metwally $M$, Jones $G L$, Wilkinson AJ, Ledger WL. Effects of cigarette smoking upon clinical outcomes of assisted reproduction: a meta-analysis. Hum Reprod Update. 2009;15:31-44. PMID: 18927070 DOI: 10.1093/ humupd/dmn046

Wise LA, Rothman KJ, Mikkelsen EM, Sørensen HT, Riis A, Hatch EE. An internet-based prospective study of body size and time-to-pregnancy. Hum Reprod. 2010;25:253-64. PMID: 19828554 DOI: 10.1093/humrep/dep360
Wissing $M L$, Bjerge MR, Olesen AI, Hoest T, Mikkelsen AL. Impact of PCOS on early embryo cleavage kinetics. Reprod Biomed Online. 2014;28:508-14. PMID: 24581983 DOI: 10.1016/j.rbmo.2013.11.017

WHO - World Health Organization. Body mass index - BMI. Copenhagen: WHO Regional Office for Europe; 2020. Available at: https://www.euro.who.int/en/health-topics/disease-prevention/nutrition/a-healthy-lifestyle/body-mass-index-bmi

Yang Z, Zhang J, Salem SA, Liu X, Kuang Y, Salem RD, Liu J. Selection of competent blastocysts for transfer by combining time-lapse monitoring and array $\mathrm{CGH}$ testing for patients undergoing preimplantation genetic screening: a prospective study with sibling oocytes. BMC Med Genomics. 2014;7:38. PMID: 24954518 DOI: $10.1186 / 1755-8794-7-38$

Zaadstra BM, Seidell JC, Van Noord PA, te Velde ER, Habbema JD, Vrieswijk B, Karbaat J. Fat and female fecundity: prospective study of effect of body fat distribution on conception rates. BMJ. 1993;306:484-7. PMID: 8448457 DOI: $10.1136 / \mathrm{bmj} .306 .6876 .484$

Zaninovic N, Irani M, Meseguer M. Assessment of embryo morphology and developmental dynamics by time-lapse microscopy: is there a relation to implantation and ploidy? Fertil Steril. 2017;108:722-9. PMID: 29101997 DOI: 10.1016/j.fertnstert.2017.10.002

Zeyad A, Al-Abdulkareem B, Hammadeh ME. The relationship between preimplantation morphokinetics of human embryos and sex chromosome pattern. Reprod Biol. 2018;18:385-9. PMID: 30344090 DOI: 10.1016/j.repbio.2018.10.002

Zhan Q, Ye Z, Clarke R, Rosenwaks Z, Zaninovic N. Direct Unequal Cleavages: Embryo Developmental Competence, Genetic Constitution and Clinical Outcome. PLoS One. 2016;11:e0166398. PMID: 27907016 DOI: 10.1371/journal.pone.0166398

Zhang J, Tao W, Liu H, Yu G, Li M, Ma S, Wu K. Morphokinetic parameters from a time-lapse monitoring system cannot accurately predict the ploidy of embryos. J Assist Reprod Genet. 2017;34:1173-8. PMID: 28676910 DOI: $10.1007 / \mathrm{s} 10815-017-0965-8$

Zhao J, Yan Y, Huang X, Sun L, Li Y. Blastocoele expansion: an important parameter for predicting clinical success pregnancy after frozen-warmed blastocysts transfer. Reprod Biol Endocrinol. 2019;17:15. PMID: 30674332 DOI: 10.1186/s12958-019-0454-2 